\title{
Embracing systematic futures thinking at the intersection of Strategic Planning, Foresight and Design
}

\author{
Jörn Bühring \\ joern.buehring@polyu.edu.hk | The Hong Kong Polytechnic University, School of Design, Hung Hom, \\ Kowloon, Hong Kong \\ Jeanne Liedtka \\ LiedtkaJ@darden.virginia.edu | The University of Virginia, Darden School of Business, Charlottesville, \\ USA
}

\begin{abstract}
In this conceptual paper, we review the literature spanning the Strategic Planning, Foresight and Design disciplines with the emphasis placed on how innovation stakeholders may engage with the future in order to explore the challenges to decision-making they highlight. From this review, and a series of facilitators identified by the authors in previous design and futures thinking field research, critical perspectives are presented that illustrate how systematic futures thinking can inform decisionmakers concerning the innovation challenges and opportunities emerging over medium and longer-term (5-15 years) time horizons of social and technology environments. Combining Foresight and Design in an approach we call "Foresight by Design", as part of Strategic Planning processes, can help the emergence of new and more creative possibilities, foster the inclusion and alignment of diverse stakeholders, and provide for ongoing learning through prototyping and experimentation by using design tools and approaches to achieve deeper insight and alignment around current reality, to facilitate a more productive conversation across difference, to aid in specifying a portfolio of desirable futures, and to engage ecosystem partners in active experimentation that generates new knowledge and learning.
\end{abstract}

Keywords. Innovation; Foresight; Design Thinking; Futures Thinking.

Cite paper as: Bühring, J., Liedtka, J., (2018). Embracing systematic futures thinking at the intersection of Strategic Planning, Foresight and Design, Journal of Innovation Management, www.open-jim.org, 6(3), $134-152$. http://hdl.handle.net/10216/116396 


\section{Introduction}

Amid accelerating environmental complexity and uncertainty, meeting the demands of rapid social, technological and environmental change draws continued attention to how organizations envision their preferred futures and strategic direction (Hamel \& Valikangas, 2003). Driven by globalization, digitization, commoditization and politicization, business leaders struggle to create and maintain competitive advantage through innovation activities, while operating in an ever-more interconnected world, where few can retain a competitive edge independently of others (Ireland \& Hitt, 1999). Across nearly all sectors of the economy, the axiom is that organizations have to respond to change in fundamentally new ways if they are to be successful in the future.

One of the particular areas of concern relates to time horizons. In spite of the wide-spread acknowledgement of growing uncertainty over the rapidly changing external macro-business environment, most product or service solutions continue to be informed by current market needs, and over the short-term (1-3 year) time horizon (Heger \& Rohrbeck, 2012; A. Wilkinson, Mayer, \& Ringler, 2014). More recently, this development has prompted a call for business leaders and educators to become more forward thinking, and to develop the organization's innovation and creative capabilities to remain feasible in the long-term (Kock, Heising, \& Gemünden, 2015; Koen et al., 2002; Meroni, 2008; Van der Laan \& Yap, 2016). Making decisions based on simply projecting today's market trends into the future is untenable (Saritas \& Smith, 2011; Vecchiato, 2015).

Three areas deeply concerned with these issues, in both theory and practice, are Strategic Planning, Foresight and Design. In each, scholars focused on thinking about the future are devoting increased attention to exploring the important question of what constitutes the most effective organizational processes for crafting successful long-term direction (Hamel, 2002; Heskett, 2009; Hofer \& Schendel, 1978; Rohrbeck, Battistella, \& Huizingh, 2015; Slaughter, 2002). But they have often done so without reference to parallel work underway in other disciplines. In this article, we address this omission by examining independently, key themes at work in these three fields, and the opportunity that integrating aspects of this work across the three areas might hold for improving the adaptability and innovation capacity of organizations though improved strategic planning processes that incorporate both Foresight and Design tools and approaches.

From our review, we draw attention to gaps in understanding of how practitioners learn to navigate disruption, make sense of complexity, and deal with uncertainty to envisage the medium and longer-term futures (5-15 years) of social and technology environments. Derived from our own previous design and futures thinking field research, key conceptual foresight facilitators are identified, which form the basis for an approach to systematic futures thinking we refer to as "Foresight by Design".

\subsection{Foresight by Design - context and definition}

One key contribution of this article is to propose for consideration how work at the intersection of these three fields could be fruitful. It argues for a new strategic and collaborative function "Foresight by Design", which combines design-led and systematic futures thinking of preferable and desirable futures, in ways that embrace their synthesis (Buhring, 2017; Buhring \& Koskinen, 
2017; Liedtka, 2017). Specifically, we argue that strategic decision-making processes can benefit from an integration of Foresight and Design techniques, thus advancing the strategic innovation decision-making conversation beyond short-term product and services aimed at meeting current market needs. Just as Futurists and Foresight consultants conduct environmental scanning to detect new events and drivers of change over the ten-year plus time horizons (Day \& Schoemaker, 2006), and as Government Policy makers and large Corporations in durable goods and process industries apply long-range futures thinking (Fuerth, 2009), organizations practicing "Foresight by Design" can better prepare to deal with uncertainty over the medium and longer-term time horizon (5-15 years), as Figure 1 suggests.

\begin{tabular}{|c|c|c|c|}
\hline $\begin{array}{l}\text { Products \& Services } \\
\text { Innovation } \\
\text { [Meeting Market Needs] }\end{array}$ & $\begin{array}{l}\text { Foresight } \\
\text { by Design } \\
\text { [dealing with } \\
\text { uncertainty] }\end{array}$ & $\begin{array}{c}\text { Mega Trends } \\
\text { [Technology Road- } \\
\text { mapping, Market trends] }\end{array}$ & $\begin{array}{l}\text { Long-range Futures Thinking } \\
\text { [Government Policies; few Corporates, } \\
\text { e.g. Shell, Toyota, BASF, VW] }\end{array}$ \\
\hline The Organization & "The Gap" & Futurist/Consultancy & Durable goods and process industries \\
\hline
\end{tabular}

Fig. 1. "Foresight by Design" - addressing the "systematic futures thinking' gap across the medium to longer-term time horizon

This kind of futures thinking would offer multi-disciplinary stakeholders a common language for employing Design thinking methodologies and Foresight techniques to inform strategic opportunities for innovation that build on shared visions of preferable or desirable futures. In this context, futures thinking can be seen as activities focused on detecting medium to longer-range opportunities and possibilities for strategic innovation (Rohrbeck, 2012, p. 445). We begin with a broader look at the literature on formal planning processes, their evolution, and the areas in need of additional research and practice improvement that scholars observe.

\subsection{The Role of Strategic Planning}

Reports of the "fall of strategic planning" (Mintzberg, 1994) are greatly exaggerated, argue Vaara and Whittington (2012) in their definitive review of scholarship around strategy as practice, published in the Annals of the Academy of Management. Despite long-standing and widespread disillusion with their organizations' strategic planning processes among executives, they remain one of the most widely used management tools. Wolf and Floyd (2017, p. 1758), in the most comprehensive review of the Strategic Planning literature to-date spanning three decades of research, define strategic planning as a "more or less formalized, periodic process that provides a structured approach to strategy formulation, implementation, and control," whose purpose is to "influence an organization's strategic direction for a given period and to coordinate and integrate deliberate as well as emerging strategic decisions." They note continuous evolution in the conceptualization of the topic, with recent emphasis on more social perspectives: while earlier studies emphasized formal techniques like SWOT and competitor analysis, and long run forecasting, strategic change and adaptation are seen as increasingly important. Both they and Vaara and Whittington (2012), highlight several important emerging areas in need of the development of both better theory and practice: (1) strategy as emergent rather than planned a 
priori; (2) the involvement of broader groups of stakeholders in planning processes, and (3) the failure to translate strategic plans into organizational outcomes.

Other scholars have explored similar weakness in planning processes. The success of a strategic plan is reliant on adequate information that informs the objectives, strategies, decision-making, and measuring of results against a set of goals (Miller \& Cardinal, 1994). The lack of certainty results from a state of having limited knowledge over the existing externalities, the future outcome, or possible outcomes (Simon, 1955). Furthermore, strategic decisions are primarily derived from interpreting information about the past and present (Mintzberg, 1994), in an environment where single point predictions are often inaccurate.

Developing an organization's strategic innovation direction against a rapidly evolving business environment poses challenges, as Mintzberg's classic indictment of planning (1994) alleges. Clark and Fujimoto (1991) also argue that the process-driven approach to strategic planning can impose constrains on creativity and the ability to imagine more disruptive innovations. Studies in the field of Strategic Management have noted that strategic planning and strategic thinking are two distinct thinking modes. Strategic thinking is intuitive, experimental and disruptive, and applied to formulate a vision of where the organization should be heading (Heracleous, 1998; Liedtka, 1998), versus strategic planning as being more formal, procedural and analytic. Yet, creativity and imagination must be considered as important factors when the objective is to detect emerging opportunities, or threats, resulting from macro drivers of change in a company outside environment. Thus, incorporating more strategic thinking into planning processes is a major concern.

Other work grounded in the social constructionist perspective has argued for a view of strategic planning as a communicative process (Spee \& Jarzabkowski, 2011), in which talk and text intersect in a recursive way that reduces variance in employees' interpretations. In a similar vein, Johnson, Prasantham, Floyd and Bourque (2010) assert that planning tools like scenarios often fail due to social dynamics, not fit, and that managing managerial anxiety through the building of community (which they refer to "communitas") and mitigating the effects of hierarchy ("antistructure") are key to accomplishing this. In each of these areas that challenge planning, we will argue, a "Foresight by Design" approach can make significant contributions.

\subsection{The Role of Foresight}

Most scholars situate Foresight activities as one segment of strategic planning processes (Cuhls, 2003; Voros, 2003). The Foresight discipline encompasses a wide range of approaches and activities designed to help business stakeholders deal with uncertainty (Inayatullah, 2008). Slaughter (2002), in Voros (2003, p.4), positions foresight applied in business as a pragmatic approach to addressing the strategic questions of how to survive in an increasing competitive environment. Foresight methodologies use techniques such as macro trend analysis and expert knowledge to explore alternative futures (Figure 2) and classify them into possible (might happen), plausible (could happen), probable (likely to happen), and preferable (wanting to happen) (Hancock \& Bezold, 1993; Voros, 2001). 


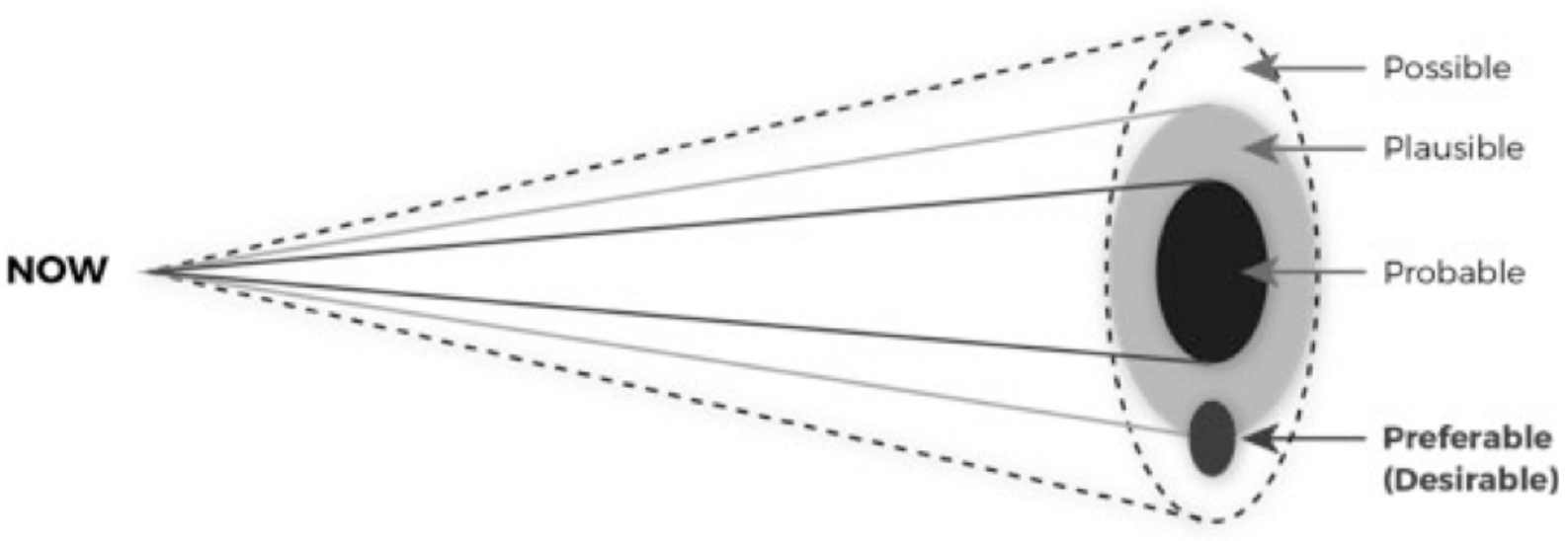

THE FUTURE

Fig. 2. The "future cone" - adapted from Hancock and Bezold (1993)

The objective of Foresight is to consider different ways (alternative futures) in which the external environment may evolve over the next 5 - 15 years, or even longer (Dator, 2009; Slaughter, 2002; Voros, 2003). To illustrate its significance, innovation stakeholders ask, "what would the response to uncertainty have to be if a future were to unfold that was distinctively different from the one anticipated in the current strategic innovation plan"? Foresight methodologies express these types of inquiries in form of futures scenario statements that help prepare for, or actively shape the future (Bishop, Hines, \& Collins, 2007). These methodologies are usually qualitative rather than quantitative in nature (Cuhls, 2003). The practice of Foresight is effective when decision-makers expand beyond subjective views of reality and consider more closely the relationship between objective reality (fact-based, measurable and observable) and possible futures (Mietzner \& Reger, 2005). Thinking about different possibilities through futures scenario building allows decisionmakers at the strategic end of innovation to envisage different future possibilities and outcomes. Consequently, a systematic approach to futures thinking is based on futures scenarios that explore holistic, integrated, and alternative futures, that contain tangible images of how preferable and desirable futures might be shaped. Contrary to the conventional practice of extrapolating trends from the present, as in forecasting, futures scenarios are speculative images of preferable and desirable futures that form a necessary foundation of the scenario planning process (Slaughter, 2000; L. Wilkinson, 1997).

Like Strategic Planning, Foresight approaches have called for broader inclusion of more "nonexpert" stakeholders (Cuhls, 2003) and have evolved to incorporate more of a social dimension (Chan \& Daim, 2012). Preferable futures, Voros (2003, p.14) notes, "are more emotional than cognitive". Inayatullah (2008) argues for a deeper level of futures thinking, beyond just adding skills through Foresight training, to enhance employees' confidence that they can create the future that they desire. Similarly, Wilkinson, Mayer and Ringler (2014) describe a highly participatory, multi-stakeholder process they term "Transformational Foresight". Both they and Hines and Zindato (2016) explicitly call for greater integration of Design practices in Foresight work.

Combining Design and Foresight offers the promise of helping decision-makers deal more effectively with uncertainty as part of the strategic planning process; based on different possibilities, 
decision-makers can select and integrate the most preferable and desirable futures. After a brief introduction to the literature on Design, we will return to look more deeply at what the specifics of combining Foresight and Design might mean for enhancing the effectiveness of Strategic Planning processes.

\subsection{The Role of Design}

Though originally focused on the new product development field, the role of Design in business has gradually expanded beyond merely creating and communicating better products and services. Design is now understood by its totality of activities in form of competencies and capabilities that span the entire innovation eco-system, involving interdisciplinary stakeholder teams responsible for creating sustainable value propositions that ensure the organization's future (Bohemia, Rieple, Liedtka, \& Cooper, 2014; Buhring, 2017; Heskett, 2001; Lojacono \& Zaccai, 2004).

At its core, Design is a hypothesis-driven process, focused on learning and iteration. A central tenet of successful Design is that it sits at the intersection of possibilities, constraints, and contingencies (Buchanan, 1992). "Design Thinking", a term popularized by the innovation consultancy IDEO, incorporates three additions to traditional Design theory. The first is the emphasis on being user-driven; Design Thinking's focus on the particular is human-centered (to a degree that its predecessors in Design theory were not) with the development of empathy considered critical to successful use of the method (Patnaik, 2009). The second addition is an emphasis on the inclusion of a more heterogeneous set of voices in the Design process, with an attendant preference for co-creation and designing with rather than for. The third is the addition of a specific set of tools and activities, drawn primarily from Graphic-, Service-, Participatory- and Product Design fields. These tools include a variety of ethnographic research techniques like observation and interviewing, journey mapping, job-to-be-done (JTBD); ideation tools like brainstorming and concept development techniques; visualization tools like mind mapping and storyboarding for prototyping; and methods for the design of experiments to test the portfolio of solutions developed. Thus, Design Thinking accompanies traditional Design approaches with a toolkit that facilitates its operationalization in practice (Liedtka, 2011).

Design is increasingly positioned as an organizational competence that looks beyond one-time creative outputs (products or services), toward Design as an organizational activity that can lead to sustained innovation and competitiveness (Boztepe, 2016; Heskett, 2001; Mozota, 1998). Related research (Buhring \& Koskinen, 2017) builds on studies of extreme users inspired by von Hippel's notion of lead users (Djajadiningrat, Gaver, \& Fres, 2000), practices in crowdsourcing (Kurvinen, Koskinen, \& Battarbee, 2008), and experience prototyping techniques (Buchenau \& Suri, 2000). A recent trend in Design is also propounding fiction as a way to envisage or create futures (Bleecker, 2009; A. Dunne \& Raby, 2013).

Progressive organizations over the past two decades have noted the favorable use of Design as a problem-solving approach, sparking the popularity of Design Thinking processes and applications toward transformative innovations in a global economy (D. Dunne \& Martin, 2006; Liedtka, 1998; Oster, 2008), with the further potential for unifying interdisciplinary stakeholder conversations that enhance a collective's ability to align, learn, and change together (Liedtka, 2017). 


\subsection{Combining Foresight and Design in Service to Strategic Planning}

Looking across these three literatures, we hypothesize that systematic futures thinking activities, in the form of "Foresight by Design", can improve strategic planning by combining Foresight's more objectively trend-based techniques with Design's subjective human-centered focus and toolkit. In this section, we offer evidence for that view by first looking at the aims of each of the three activities, and then at the tools they offer to practitioners. Finally, we consider the different ways each enters the futures conversation and what that suggests for the particular aspects of the future they are likely to focus on.

Beginning then, with the intent behind the deployment of each, we start with Foresight. Cuhls (2003) notes that the aims of foresight approaches include (among others): enlarging the choice of opportunities, ascertaining new needs and possibilities, defining desirable and undesirable futures, and stimulating continuous discussion. Not surprisingly, accomplishing each one of these aims is clearly essential to successful strategy-making processes operating in uncertain environments. Interestingly, these are also core aims of Design processes as well. Much of the Design Thinking tool kit aims at discovering unmet user needs and preferred futures, enlarging the opportunity space by reframing the problem, and creating a dialogue-based inquiry process to facilitate co-creation across diverse stakeholder groups (Ogilvie \& Liedtka, 2011).

Even more interesting, given these shared ambitions, is the extent to which the tools related to each field are not shared, as a listing of selected tools in each illustrates:

- Strategic Planning: SWOT (strengths, weaknesses, opportunities, \& threats), industry and competitor analysis, cognitive mapping

- Foresight: Delphi methods, environmental scanning, causal layered analysis, scenarios

- Design Thinking: ethnographic interviewing and observation, journey mapping, Job-to-bedone (JTBD), brainstorming, prototyping, and experimentation

The only tool overlapping all three methods is the use of scenarios, and even here, the deployment of that tool varies across the fields, as Hines and Zindato (2016) illustrate. In Design practice, typically, scenarios are developed to communicate, validate and endorse design decisions about user actions (Evans, 2003; Martin, 2009). In Foresight, scenarios are developed as stories about alternative futures at macro scale, or across whole systems (Hines \& Zindato, 2016; Rasmussen, 2005).

In Design practice, the use of scenarios at varying stages of the innovation process is, more commonly, closely aligned with detecting insights from users addressing their current needs (Martin, 2009). While in Foresight practice, scenarios are used to create stories about how futures might develop, and what should be done to prepare for these eventual changes in the organizations' surrounding environment (Chan \& Daim, 2012; Slaughter, 1995). Thus, each of the three literatures, though sharing intentions, approaches the question of the future in very different ways. This suggests that combining these toolkits, in ways that they work together, could be powerful. They are likely to be specifically useful in relation to the three challenges highlighted in the Strategic Planning literature earlier in our discussion: involvement, emergence, and translation to action.

More support for the synergistic value in their combination is revealed by an examination of 
their respective starting points for entry into the futures conversation. Using Buchanan's (1992) observation about the importance of the intersection of possibility, constraint, and contingency in thinking well about the future, we observe differences that are potentially valuable in bridging. Traditionally, foresight processes focus on the contingency dimension as entry point, building future scenarios based on key trends and uncertainties in order to lay out a set of plausible futures. Design takes possibilities as its starting point, laying out a portfolio of concepts based on the question "what if anything were possible? Traditional strategic planning processes often begin with the constraints of current capabilities and resources, and what would need to change to create a different future.

Each element - possibilities, constraints, and contingencies - is critical to the development of strategic innovation intent toward a powerful future in a changing environment, but an overemphasis on any of them risks problems: beginning with constraints which can trap practitioners in status quo thinking and stunt their imagination (as Mintzberg and others suggest). But conceiving of possibilities without considering constraints, though stimulating to creativity, is unlikely to lay the groundwork for successful implementation of new ideas. And an early emphasis on uncertainty carries the risk of paralyzing decision-makers or making them reactive, creating a sense of powerlessness to actively shape a strategic innovation vision of the future. Hence, a successful future-focused process must accomplish all three elements, and in an iterative way that allows possibilities to surface, considers constraints without disabling imagination, and factors in uncertainties without creating powerlessness. This dilemma also relates to (Hancock \& Bezold, 1993) future cone. Whereas the Design Thinking realm is likely to generate preferred scenarios (in the eyes of users), Foresight is likely to generate possible scenarios (based on trends and embracing uncertainties), while the traditional planning process is generating probable ones (based on today's constraints) and preferred ones (based on the organization's needs). Again, the gestalt of bridging the three practice fields is evident.

Thus, the role of Design and its creative thinking, scenario-building, visualization, and prototyping competencies may help produce tangible images that further advance collective visions of strategic innovation futures as preferable, and indeed desirable (Buhring, 2017; Buhring \& Koskinen, 2017; Heskett, 2001; Koh, Slingsby, Dykes, \& Kam, 2011; Manzini \& Vezzoli, 2003). The advantages of futures thinking, moreover, can lead to the creation of future value, and the development of perceptions about futures that may inform the decisions or strategies needed to prepare for alternative possibilities (A. Wilkinson et al., 2014). While most organizations fail to look beyond a narrow set of factors, evidence suggests that firms who have recognized the value of futures thinking and strategic design approaches as an important resource in the innovation process, are indeed those who achieve sustainable competitive advantages (Grant, 2010; Heskett, 2009; Mankoff, Rode, \& Faste, 2013; Martin, 2009).

Consequently, across both fields an obvious relationship evolves around the use of scenarios as evidence-based narratives, which are ultimately designed to help innovation teams, and their organization, identify and make better informed choices in the present. To this end, the linkage between Design and Foresight principles become hybrid futures thinking techniques that inform both the 'what?' is changing over the medium to longer-term horizon (5-15 years), and the 'how?' this may translate into creative and innovative images and narratives of possible futures.

As Design and Foresight grow closer together in service to enhanced planning processes (Buhring, 
2017; Evans, 2012; Hines \& Zindato, 2016), a deeper understanding is needed of how this collaboration would operate in practice, the topic to which we now turn.

\section{Key Conceptual Futures Thinking Factors}

Derived from cross-disciplinary insights, and our own research in Design and Foresight studies, the hypotheses around the broader role of the strategic design conversation, is to include systematic futures thinking as a transformational approach to producing visions of desirable futures. Resulting from theoretical and applied field research, a series of conceptual 'high-level' futures thinking factors were identified as:

1. Achieving insights and alignment around current reality

2. Facilitating a productive Design conversation

3. Specifying a portfolio of desirable futures

4. Active experimentation to gather new knowledge and learning

\subsection{Achieving Insight and Alignment around Current Reality}

Though the future might appear to be the most logical initial emphasis in Foresight work, one contribution of Design to Foresight is to insist on grounding discussions of the future in an immersion in the reality of today, with a focus on both gaining deep and novel insights into today's challenges and customer pain points and establishing alignment across critical stakeholders about key elements of the present situation (Gabrielli \& Zoels, 2003; A. Wilkinson et al., 2014). This aims to accomplish two ends. The first is to facilitate reframing of the initial question, by challenging decision-makers to examine the assumptions they are bringing into the definition of the problem itself, opening up a wider array of choices. The second is to work towards aligning the views of key stakeholders around critical design criteria that describe the ideal future, ensuring coherence and commitment in a more inclusive conversation across a broader group of stakeholders. On the demand side, design tools like job-to-be-done (JTBD) and journey mapping offers methods that allow innovators to pursue deeper insights into current reality (Bucolo \& Matthews, 2011), facilitated by the development of empathy for those to be served that firsthand ethnographic data collection encourages. On the supply side, capability mapping aids in the important work of accurately assessing the kinds of experiences that the organization is capable of producing. Taken together, this allows highlighting of the experience gap between the experience desired by the customer and that currently delivered by the organization. Identification of the experience gap is the step that facilitates the design of strategies that address future scenarios.

- Case study example 1: In a recent 2030 futures study involving a heterogeneous group of industry experts in the financial services sector (Buhring, 2017), the Delphi method was used as a basis for foresight. In the first Delphi survey round, the objective was to ignite a conversation around the prevailing innovation system, and probe deeper into what defines the current "status quo". Data analyzed at the end of this survey round provided important insights as to which products and services are considered as drivers of continues 
growth. Similarly, the data highlighted that the focus was placed on innovations addressing current customer needs. Due to the diversity of participants in both their backgrounds, perspectives, and experiences, a broad range of opinions were recorded as to what are the signs of change that would have impact on the organization. Hence, establishing what is going on today, and aligning the perspectives across relevant stakeholders in the innovation eco-system, befalls as an important factor in initiating and practicing futures thinking (see Curry \& Hodgson, 2008; Morrison \& Wilson, 1997).

\subsection{Facilitating a Productive Design Conversation}

An important goal of the design conversation is emergence: the development of previously unseen possibilities that emerge when a group of stakeholders with diverse perspectives are involved in a generative conversation, in contrast to an evaluative one (whose starting point is a set of existing identifiable options). In order to accomplish this, the conversation must achieve two things: (1) finding a blend of inquiry and advocacy and (2) leveraging the diversity within the conversation to produce higher order solutions rather than divisive debates. The two are closely related.

An essential aspect of successful design work is the engagement of critical players in the larger ecosystem, outside of the organization itself. It is through mutual learning and cooperation among these players that shaping behaviors, aimed at making preferred scenarios a reality in the future, is coordinated. But turning the theoretical diversity these players bring into the formulation of more creative, shared scenarios, requires changing the nature of the conversation itself to incorporate an increasing role for dialogue as well as debate, for inquiry as well as advocacy. Participants in such conversations must listen to understand rather than defend, and for possibilities rather than weaknesses. Design Thinking's tools for collaborative problem solving can assist the search for higher-order solutions, by offering a structured process in which that dialogue and inquiry occurs, and where divergent views are surfaced and explored, rather than relying solely on the skills of the leader of the conversation. These conversations must also occur at different levels: the ecosystem, the organization itself, and the functional and local levels within it. It is these nested and coordinated conversations that make possible the translation of abstract strategies into actionable new ways of thinking and behaving.

- Case study example 2: Resultant from the aforementioned 2030 futures study (Buhring, 2017), a series of futures scenario statements were produced as consensus toward the Delphi panels' combined vision of preferable or desirable futures. From this research, a subsequent study phase was initiated to expand on the stories and narratives contained in each scenario at a deeper level, thus moving the Design conversation from information gathering, to processing the inherent cues for specific potential new futures. A key observation in this study phase was noticed by Designers and interdisciplinary innovation practitioners who questioned the dominant business logic, which in context of the traditional financial services business and operating model, was considered in conflict between the embedded present and these imagined futures. 


\subsection{Specifying a Portfolio of Desirable Futures}

Whereas scenario building might tend to focus on possible and plausible futures, Design brings a strong emphasis on specifying a set of preferred futures. In this way, its intent lies more with shaping the future than merely responding to it. Like scenario planning, the emphasis is on optionality - specifying a range of different future options. Design tools here assist decisionmakers to construct that portfolio of alternatives with an eye towards timing, by surfacing assumptions around impact on the demand side relative to ease of implementation on the supply side, with capability development a critical factor.

Design also suggests that new futures, in order to become realities, must be experienced, rather than merely thought: more than cognitive, they must be vivid, personally meaningful, and compelling to the members of the organization who must adopt new behaviors in order to execute them. The idea of experiencing a new future in an emotional as well as cognitive way is grounded in an interpretive, socially constructed perspective, rather than an objectively rational one (Andrews, 2012). One core dilemma in moving an organization into a new future, then, is how to make new ideas tangible. Architects build models, Product Designers construct prototypes (Buhring \& Koskinen, 2017) - but prototyping a new future is more challenging to envision. This is where Design's emphasis on visualization tools like storytelling and journey mapping contribute to Foresight work.

- Case study example 3: An enterprise software firm used Design Thinking to explore and discuss potentially disruptive changes in their industry. The company melded Design Thinking's emphasis on visualization and storytelling with traditional approaches to Strategic Foresight in order to compose and communicate new strategies. Carefully constructed prototypes told the story of the strategic imperative they faced at varying levels of detail from the high-level warning of the potential obsolescence of their core capabilities to the plight of a salesperson responding to a customer's pricing request. From executive dashboard to salesperson's inbox, the connections were illuminated. The prototypes not only engaged; they clarified, allowing people at different level to better understand the specifics of how the new futures impacted their roles and activities.

\subsection{Active Experimentation to gather new Knowledge and Learning}

Design's emphasis on learning in action offers a final and powerful contribution to enhancing the strategic planning process when used in conjunction with Foresight: assumptions underlying the future scenarios can be surfaced and tested through experiments in the present. In engaging ecosystem players, at different levels, in the design and execution of these experiments, learning becomes on-going and scenarios can be adjusted as real-world feedback informs the process.

- Case study example 4: From the analysis of data obtained at the completion of the 2030 Financial Services Delphi futures study (Buhring, 2017), a Design Foresight visioning approach provided further opportunities to apply data visualization and storytelling techniques. For example, utilizing storytelling narratives and imaginary creations, serves as an effective way to engage with the intended readership of a Design Foresight study in both entertaining, informing, and energizing ways. Stories can change or enhance readers' per- 
ceptions of futures, seeing themselves in different perspectives, and identifying their "self" by interpreting and completing the story in his or her head (Sametz \& Maydoney, 2003). In this 2030 futures study, personas were created that embodied the essence of futures scenario statements in verbal and non-verbal communications intended to connect the reader on both analytical and emotional levels (Figure 3).

\section{PRELLDE}

\section{PRIVATE BANK 2030: THE HUMAN FACTOR}

A top young media star takes a job in a next-generation private bank, and is intrigued to see how banking has evolved.

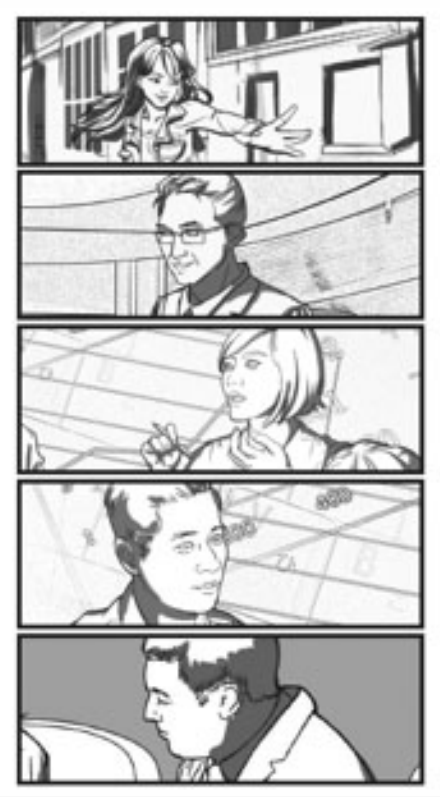

ELENI ZHAO LAL

She is the zoltoplat which makes her thair beet chance of soding the firture

FRANK CASTOR

Node chlef Frark is a plupoed-in bark bose tilke no other

\section{PAMELA XI CHEN}

Pamela has her finger on the pilse of the world's blgpest economy

\section{$\triangle H-L L M L O$}

Tech-chile Ah-Lum swloches seamlesely becween humars and $A$

\section{ADITI DAS}

The dival mine knows whom to sign up in partreershlp deals

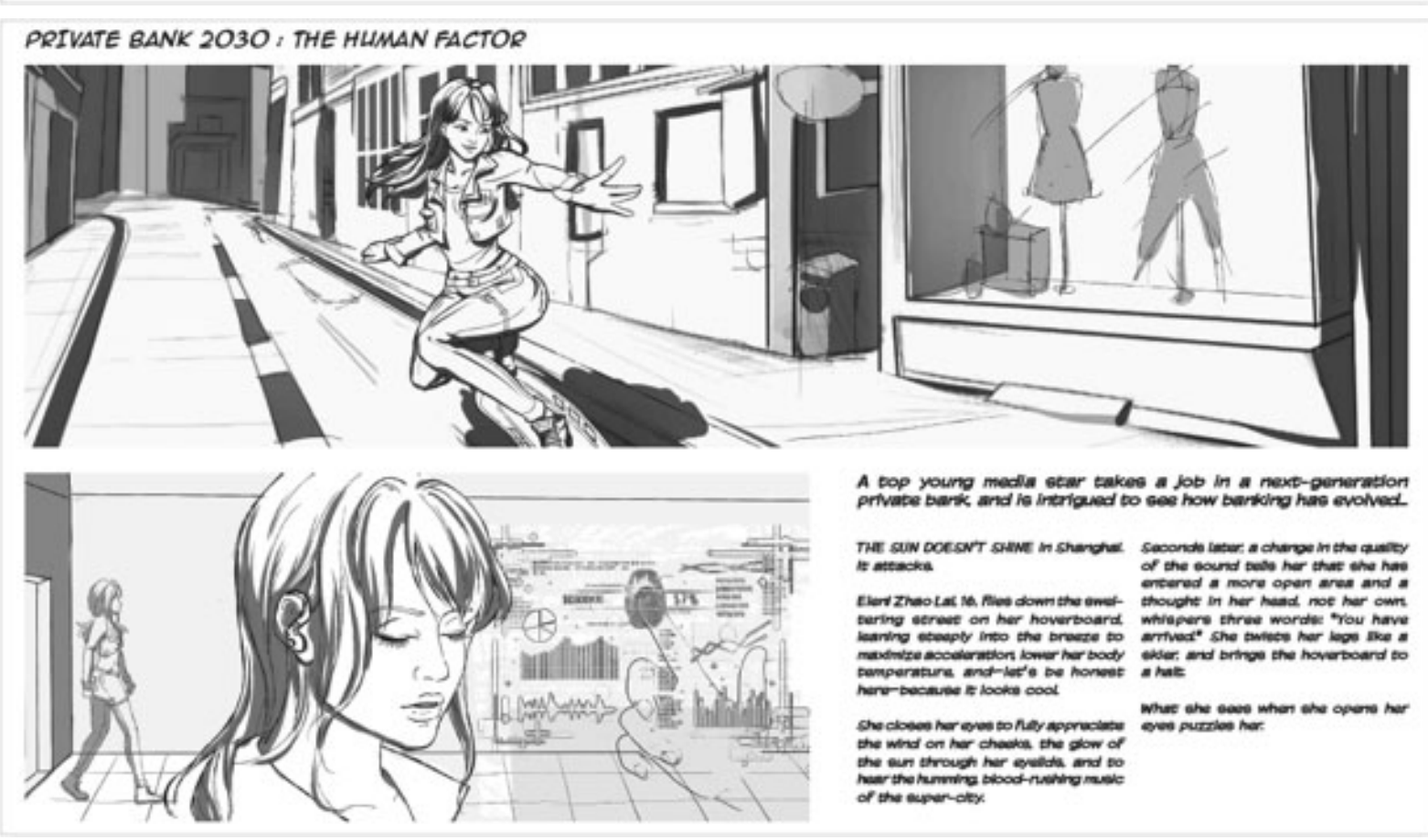

Fig. 3. Data visualization in form of storytelling persona and narratives (extract) 


\section{Conclusion}

Practicing systematic futures thinking, enhanced by Design tools and approaches, can enhance Strategic Planning's ability to foster innovation by detecting early warning signs of change and giving deeper insights into the phenomenon behind these signs. Thus, applying systematic futures thinking, through a process we refer to as "Foresight by Design," enhances concrete knowledge and processes for strategic innovation. However, as we have highlighted in this conceptual paper, there is to-date little real understanding into how designers and interdisciplinary innovation practitioners work in concert to navigate disruption, make sense of complexity, and deal with uncertainty in order to envisage the medium and longer-term futures (5-15 years). This represents a significant opportunity for both research and practice moving forward.

This conceptual approach may also offer important contributions for overcoming weaknesses in aligning Strategy, Innovation and Foresight functions. Consequently, we argue for acknowledgement of an ever-growing need for Innovation, Design, and Foresight stakeholders to work more closely together to make possible envisaging higher order, more innovative and sustainable solutions that will yield the greatest economic and social benefits (Buhring, 2017; Heskett, 2009; Hines \& Zindato, 2016; Liedtka, 1998; Meroni, 2008; Slaughter, 2002).

To this end, we have advanced in this conceptual paper some hypotheses around a broader role for the strategic Design conversation to enhance systematic futures thinking and produce potentially transformational visions of desirable futures. While there are many methods in Design and Foresight disciplines relevant to opportunity identification, the value of systematic futures thinking is based on the strategic production of visions of desirable futures (scenarios), which can help inform decision-makers about the innovation challenges and opportunities that will emerge over the medium and longer-term time horizon (Buhring, 2017; Buhring \& Koskinen, 2017; Kock et al., 2015). The desired futures thinking outcomes we hypothesize, however, are unlikely to be achieved through short-term, sporadic, or superficial Design Thinking approaches, as its processes need to be understandable and collaboratively used by all strategic innovation stakeholders. Further limitations are acknowledged in the organizational practice of Foresight in Design research, and its objective evaluation of performance and contribution over existing Strategic Planning approaches.

To this end, the review of the Strategic Planning, Design and Foresight literature, and knowledge gained from our own applied field research, have identified key conceptual Foresight factors that can help integrate systematic futures thinking at the front end of innovation. These include using Design tools and approaches to achieve deeper insight and alignment around current reality, to facilitate a more productive Design conversation, to aid in specifying a portfolio of desirable futures, and to engage ecosystem partners in active experimentation that generates new knowledge and learning. 


\section{References}

Andrews, T. (2012). What is social constructionism. Grounded theory review, 11(1), 39-46.

Bishop, P., Hines, A., \& Collins, T. (2007). The current state of scenario development: an overview of techniques. foresight, 9(1), 5-25.

Bleecker, J. (2009). Design fiction. A short essay on design, science, fact and fiction. Near Future Laboratory.

Bohemia, E., Rieple, A., Liedtka, J., \& Cooper, R. (2014). Proceedings of the 19th DMI: Academic Design Management Conference: Design Management in an Era of Disruption: Design Management Institute.

Boztepe, S. (2016). Design expanding into strategy: evidence from design consulting firms. Paper presented at the DRS 2016 Internatinoal Conference, Brighton, UK.

Buchanan, R. (1992). Wicked problems in design thinking. Design Issues, 8(2), 5-21.

Buchenau, M., \& Suri, J. F. (2000). Experience prototyping. Paper presented at the Proceedings of the 3rd conference on Designing interactive systems: processes, practices, methods, and techniques.

Bucolo, S., \& Matthews, J. H. (2011). A conceptual model to link deep customer insights to both growth opportunities and organisational strategy in SME's as part of a design led transformation journey. Design management toward a new Era of innovation.

Buhring, J. (2017, 7-9 June 2017). Design-inspired Foresight: Strategic foresight techniques for preferable futures. Paper presented at the Design Management Academy, Hong Kong, China.

Buhring, J., \& Koskinen, I. (2017, 31 October - 3 November 2017). Beyond Forecasting: A Design-inspired Foresight Approach for Preferable Futures. Paper presented at the International Association of Societies of Design Research, Cincinnati, USA.

Chan, L., \& Daim, T. (2012). Exploring the impact of technology foresight studies on innovation: Case of BRIC countries. Futures, 44(6), 618-630.

Clark, K. B., \& Fujimoto, T. (1991). Product development performance: Strategy, organization, and management in the world auto industry: Harvard Business Press.

Cuhls, K. (2003). From forecasting to foresight processes - new participative foresight activities in Germany. Journal of forecasting, 22(2-3), 93-111.

Curry, A., \& Hodgson, A. (2008). Seeing in multiple horizons: connecting futures to strategy. Journal of Futures Studies, 13(1), 1-20.

Dator, J. (2009). Alternative futures at the Manoa School. Journal of Futures Studies, 14(2), $1-18$.

Day, G. S., \& Schoemaker, P. J. (2006). Peripheral vision: Detecting the weak signals that will make or break your company: Harvard Business Press. 
Djajadiningrat, J. P., Gaver, W. W., \& Fres, J. (2000). Interaction relabelling and extreme characters: methods for exploring aesthetic interactions. Paper presented at the Proceedings of the 3rd conference on Designing interactive systems: processes, practices, methods, and techniques.

Dunne, A., \& Raby, F. (2013). Speculative everything: design, fiction, and social dreaming: MIT Press.

Dunne, D., \& Martin, R. (2006). Design thinking and how it will change management education: An interview and discussion. Academy of Management Learning $\mathcal{E}$ Education, 5(4), $512-523$.

Evans, M. (2003). Trend forecasting for design futures. Paper presented at the 5th European Academy of Design, 5th International Conference, Barcelona, Spain.

Evans, M. (2012). Designing next-next generation products and services: A design-led futures framework. Paper presented at the DRS 2012 Bangkok, Bangkok, Thailand.

Fuerth, L. S. (2009). Foresight and anticipatory governance. foresight, 11(4), 14-32.

Gabrielli, S., \& Zoels, J.-C. (2003). Creating imaginable futures: using human-centered design strategies as a foresight tool. Paper presented at the Proceedings of the 2003 conference on Designing for user experiences.

Grant, R. (2010). Contemporary Strategy Analysis Blackwell Publishing: Oxford.

Hamel, G. (2002). Leading the Revolution: How to Thrive in Turbulent Times by Making Innovation a Way of Life: Harvard Business School Press.

Hamel, G., \& Valikangas, L. (2003). The quest for resilience. Harvard Business Review, 81(9), $52-65$.

Hancock, T., \& Bezold, C. (1993). Possible futures, preferable futures. Paper presented at the The Healthcare Forum Journal.

Heger, T., \& Rohrbeck, R. (2012). Strategic foresight for collaborative exploration of new business fields. Technological Forecasting and Social Change, 79(5), 819-831.

Heracleous, L. (1998). Strategic thinking or strategic planning? Long Range Planning, $31(3)$, 481-487.

Heskett, J. (2001). Past, present, and future in design for industry. Design Issues, 17(1), $18-26$.

Heskett, J. (2009). Creating economic value by design. International Journal of Design, 3(1).

Hines, A., \& Zindato, D. (2016). Designing Foresight and Foresighting Design: Opportunities for Learning and Collaboration via Scenarios. World Future Review, 8(4), 180-192.

Hofer, C. W., \& Schendel, D. (1978). Strategy formulation: Analytical concepts: West Publ. Inayatullah, S. (2008). Six pillars: futures thinking for transforming. foresight, 10(1), 4-21.

Ireland, R. D., \& Hitt, M. A. (1999). Achieving and maintaining strategic competitiveness in the 
21st century: The role of strategic leadership. The Academy of Management Executive, 13(1), 43-57.

Johnson, G., Prashantham, S., Floyd, S. W., \& Bourque, N. (2010). The ritualization of strategy workshops. Organization Studies, 31(12), 1589-1618.

Kock, A., Heising, W., \& Gemünden, H. G. (2015). How ideation portfolio management influences front-end success. Journal of Product Innovation Management, 32(4), 539-555.

Koen, P. A., Ajamian, G. M., Boyce, S., Clamen, A., Fisher, E., Fountoulakis, S., . . . Seibert, R. (2002). Fuzzy front end: effective methods, tools, and techniques: Wiley, New York, NY.

Koh, L. C., Slingsby, A., Dykes, J., \& Kam, T. S. (2011). Developing and applying a user-centered model for the design and implementation of information visualization tools. Paper presented at the 15th International Conference on Information Visualisation.

Kurvinen, E., Koskinen, I., \& Battarbee, K. (2008). Prototyping social interaction. Design Issues, $24(3), 46-57$.

Liedtka, J. (1998). Linking strategic thinking with strategic planning. Strategy 85 Leadership, $26(4), 30$.

Liedtka, J. (2011). Learning to use design thinking tools for successful innovation. Strategy $\&$ Leadership, 39(5), 13-19.

Liedtka, J. (2017, 7-9 June 2017). Beyond Better Solutions: Design Thinking as a Social Technology. Paper presented at the Design Management Academy, Hong Kong, China.

Lojacono, G., \& Zaccai, G. (2004). The evolution of the design-inspired enterprise. MIT Sloan Management Review, 45(3), 75.

Mankoff, J., Rode, J. A., \& Faste, H. (2013). Looking past yesterday's tomorrow: using futures studies methods to extend the research horizon. Paper presented at the Proceedings of the SIGCHI Conference on Human Factors in Computing Systems.

Manzini, E., \& Vezzoli, C. (2003). A strategic design approach to develop sustainable product service systems: examples taken from the 'environmentally friendly innovation'Italian prize. Journal of cleaner production, 11(8), 851-857.

Martin, R. L. (2009). The design of business: why design thinking is the next competitive advantage: Harvard Business Press.

Meroni, A. (2008). Strategic design: where are we now? Reflection around the foundations of a recent discipline. Strategic Design Research Journal, 1(1), 31-28.

Mietzner, D., \& Reger, G. (2005). Advantages and disadvantages of scenario approaches for strategic foresight. International Journal of Technology Intelligence and Planning, 1(2), 220239.

Miller, C. C., \& Cardinal, L. B. (1994). Strategic planning and firm performance: A synthesis of more than two decades of research. Academy of management journal, 37(6), 1649-1665.

Mintzberg, H. (1994). The fall and rise of strategic planning. Harvard Business Review, 72(1), $107-114$. 
Morrison, J. L., \& Wilson, I. (1997). Analyzing environments and developing scenarios for uncertain times. Planning and Management for a Changing Environment. Jossey-Bass: San Francisco.

Mozota, B. B. (1998). Structuring strategic design management: Michael Porter's value chain. Design Management Review, 9(2), 26-31.

Ogilvie, T., \& Liedtka, J. (2011). Designing for growth: A design thinking toolkit for managers: Columbia University Press.

Oster, G. W. (2008). Practitioners corner: Derailing design thinking. International Journal of Leadership Studies, 4(1), 107-115.

Patnaik, D. (2009). Wired to care: How companies prosper when they create widespread empathy: Ft Press.

Rasmussen, L. B. (2005). The narrative aspect of scenario building-How story telling may give people a memory of the future. AI 85 society, 19(3), 229-249.

Rohrbeck, R. (2012). Exploring value creation from corporate-foresight activities. Futures, $44(5), 440-452$.

Rohrbeck, R., Battistella, C., \& Huizingh, E. (2015). Corporate foresight: An emerging field with a rich tradition. Technological Forecasting and Social Change, 101, 1-9.

Sametz, R., \& Maydoney, A. (2003). Storytelling through design. Design Management Journal (Former Series), $14(4), 18-34$.

Saritas, O., \& Smith, J. E. (2011). The Big Picture-trends, drivers, wild cards, discontinuities and weak signals. Futures, 43(3), 292-312.

Simon, H. A. (1955). A behavioral model of rational choice. The quarterly journal of economics, 69(1), 99-118.

Slaughter, R. (1995). The foresight principle: Cultural recovery in the 21st century: Praeger Publishers.

Slaughter, R. (2000). Futures tools and techniques: Futures Study Centre.

Slaughter, R. (2002). New thinking for a New Millennium: The knowledge base of futures studies: Routledge.

Spee, A. P., \& Jarzabkowski, P. (2011). Strategic planning as communicative process. Organization Studies, 32(9), 1217-1245.

Vaara, E., \& Whittington, R. (2012). Strategy-as-practice: Taking social practices seriously. Academy of Management Annals, 6(1), 285-336.

Van der Laan, L., \& Yap, J. (2016). Foresight 8 Strategy in the Asia Pacific Region: Springer.

Vecchiato, R. (2015). Strategic planning and organizational flexibility in turbulent environments. foresight, 17(3), 257-273. 
Voros, J. (2001). Reframing environmental scanning: an integral approach. foresight, 3(6), 533-551.

Voros, J. (2003). A generic foresight process framework. foresight, 5(3), 10-21.

Wilkinson, A., Mayer, M., \& Ringler, V. (2014). Collaborative futures: Integrating foresight with design in large scale innovation processes-seeing and seeding the futures of Europe. Journal of Futures Studies, 18(4), 1-26.

Wilkinson, L. (1997). How to Build Scenarios: Planning for "long fuse, big bang" problems in an era of uncertainty. Wired, San Francisco, 5, 74-81.

Wolf, C., \& Floyd, S. W. (2017). Strategic planning research: Toward a theory-driven agenda. Journal of Management, 43(6), 1754-1788. 


\section{Biographies}

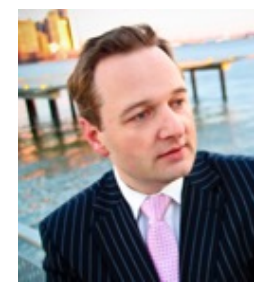

Jörn Bühring. Dr. Jörn Bühring is an Assistant Research Professor at the Hong Kong Polytechnic University, School of Design. He earned a BA-equivalent degree in the field of Tourism Management (HH), an M.B.A. (VU) majoring in Entrepreneurship and Innovation, and a PhD in futures Consumer Engagement Innovation at Swinburne University of Technology (SWIN) in Australia. In his current position, he is developing a collaborative approach (Design Economies, Ignite Innovation) that brings academia, designers, and business stakeholders together to develop high-impact design knowledge, concepts, and solutions. His research explores Design Foresight, Vision and Fiction techniques as emerging processes within Strategic Design and Innovation Management. An honorary Adjunct Associate Professor within the College of Business at RMIT University, he collaborates with leading Universities in research and design-led innovation. He gained international work experiences in corporate leadership throughout various industry, company and project initiatives, including innovative start-ups, new business formations, and new market entries. He has worked across a wide range of global brand icons (e.g. Bang \& Olufsen A/S), organizational cultures, and international markets.

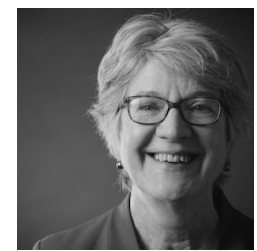

Jeanne Liedtka. Jeanne Liedtka is a professor at the Darden Graduate School of Business at the University of Virginia, where she teaches both MBAs and executives on the topics of design thinking, strategy, and innovation. Jeanne received her DBA in management policy from Boston University and her MBA from Harvard Business School. Beginning her career as a strategy consultant for the Boston Consulting Group, she has served as Associate Dean of the MBA Program at Darden, Executive Director of the Batten Institute, and Chief Learning Officer at United Technologies Corporation. Jeanne has written six books on the subject of innovation and design thinking, including: The Catalyst, How You Can Lead Extraordinary Growth, Designing for Growth: A design thinking tool kit for managers, The Physics of Business Growth, Solving Business Problems with Design Thinking: Ten Stories of What Works, The Designing for Growth Field Book: A Step-by-Step Project Guide and Design Thinking for the Greater Good: Innovation in the Social Sector. Her current research interests focus on exploring the impact of design thinking in organizations and how it can be taught and scaled. 